\title{
Nurses' help in psychiatric out-patient clinics: saving time or saving value
}

\author{
C. Brooker and S. Read
}

The paper by Meats \& Ashton (pp. 677-679, this issue) describes how an ' $E$ ' grade mental health nurse was recruited to elicit and present clients' histories in an out-patient clinic, in order to enable the consultant psychiatrist to see more clients in a session. Some greater capacity was required to help overcome the twin problem of a shortage of psychiatrists attempting to assess an increasing volume of clientele. The paper emphasises that clinical responsibility remains with the psychiatrist, and further that clinical supervision is provided through medical, not nursing, channels. The nurse in this scenario appears to be acting as a 'physicians assistant', rather extending the nursing role such as has been demonstrated in some mental health 'nurse-led' models of care, for example, behavioural nurse therapy (Marks, 1985), family psychosocial intervention in schizophrenia (Brooker et al, 1994) or deliberate self-harm (Catalan et al, 1980).

Indeed, the role of the mental health nurse, as outlined by Meats \& Ashton, would seem to have more in common with the work of pre-operative assessment nurses in acute care (Read \& Graves, 1994). Many such posts have been developed in response to the reduction in the availability of junior doctors, but they have resulted not just in a saving of medical time, but have also improved the patient's continuity of care and reduced cancelled operations (Rudkin et al, 1993).

The development of nurses as physicians assistants', rather than expanding nursing practice per se, may have dangers and difficulties. There have been reports that such roles can cause ambiguity and confusion, particularly in relation to accountability (Dowling, 1996), and if the post is full-time, the nurse may become detached from his or her nursing colleagues and end up in a professional 'blind-alley'.

Two Department of Health funded projects based at the School of Health and Related Research and the School of Nursing at the University of Sheffield, are currently exploring new roles in nursing and the professions allied to medicine (because the expansion of roles is not unique to nursing, see for example, Durrell
(1996)) and investigating the educational preparation necessary for such roles. However, many nurses, doctors and therapists see the development of multi-professional clinical teams as the way forward rather than task-focused delegation of one aspect of the clinical process (Reilly et al, 1996).

In mental health, as well as other clinical fields, this will have huge implications for multidisciplinary postgraduate education and training. Many National Health Service Trusts have begun to identify this type of educational model as the basis for the future of evidence-based community mental health care. Indeed, the West Midlands Regional Educational Development Group has already committed expenditure to a multi-disciplinary Masters programme to be based at the University of Birmingham. A similar course has existed at the University of Sheffield for two years.

The paper by Meats \& Ashton is none the less a fascinating one. Perhaps it would be useful to seek funding for a more ambitious study that prospectively evaluated the model in a number of centres examining both cost and a range of client outcomes. A study like this could identify the cost-effectiveness of the arrangement and whether or not nurses' perceptions of work as a 'physicians assistant' were positive.

\section{References}

BROOKER, C., FALLOON, I., BUTTERWORTH, C., et al (1994) The outcome of training community psychiatric nurses to deliver psychosocial intervention. British Journal of Psychiatry. 165, 222-230.

Catalan, J., Marsack, P., Hawton, K., et al (1980) Comparison of nurses and doctors in the assessment of deliberate self-poisoning patients. Psychological Medicine, 10, 483-491.

DowLING, S. (1996) Nurses taking on junior doctor's work: a confusion of accountability. British Medical Journal 312. $1211-1214$.

DURRELL, S. (1996) Expanding the scope of physiotherapy: clinical physiotherapy specialists in consultants clinics. Manual Therapy. 1, 210-213. 
Marks, I. (1985) Psychiatric Nurse Therapists in Primary Care: The Expansion of Advanced Clinical Roles in Nursing. London: Royal College of Nursing.

READ, S. \& GRAVES, K. (1994) Reduction of Junior Doctors Hours in the Trent Region: The Nursing Contribution Sheffield: Trent Royal Health Authority/National Health Service Executive.

ReIlly, C., BARRet, A., Challands, A. et al (1996) Professional Roles in Anaesthetics: A Scoping Study. Leeds: Leeds NHS Executive.
RUDKIN, G., OsBoRNE, G. \& DOYLE, C. (1993) Assessment and selection of patients for day surgery in a public hospital. Medical Journal of Australia, 168, 308-312.

C. Brooker, Professor of Nursing, University of Manchester; and S. Read, Senior Lecturer, School of Health and Related Research, University of Sheffleld, Regent Court, 30 Regent Street, Sheffield S1 4DA

\section{College Seminars Series}

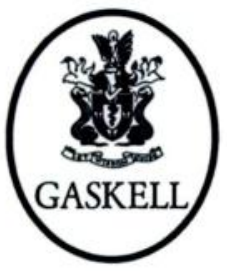

Seminars in

\section{Liaison Psychiatry}

\section{Edited by Elspeth Guthrie and Francis Creed}

Moving from the psychiatric in-patient and out-patient settings to the general medical wards can be disorientating and difficult. The clinical problems are different. In this text, recognised experts in liaison psychiatry guide the trainee through the various difficulties of interviewing, assessing and formulating the psychological problems found in patients in general medical units. $f$ I5.00, 3/2pp., 1996, ISBN 0902241958

Available from good bookshops and from the Publications Department, Royal College of Psychiatrists, 17 Belgrave Square, London SWIX 8PG. Credit card orders can taken over the telephone $(+44(0)$ I 7 I-235 235I, extension 146).

The latest information on College publications is on the INTERNET at http://www.demon.co.uk/rcpsych/ 